\title{
TNFR, TRAF2, NF-KB mRNA Levels of Glioblastoma Multiforme Cells Treated by Conditioned Medium of Umbilical Cord-derived Mesenchymal Stem Cells
}

\author{
Novi Silvia Hardiany ${ }^{1}$, Yohana ${ }^{2,3}$, Septelia Inawati Wanandi ${ }^{1, *}$ \\ ${ }^{1}$ Department of Biochemistry and Molecular Biology, Faculty of Medicine, Universitas Indonesia, Jl. Salemba Raya No.6, Jakarta, Indonesia \\ ${ }^{2}$ Master Program in Biomedical Sciences, Faculty of Medicine, Universitas Indonesia, Jl. Salemba Raya No.6, Jakarta, Indonesia \\ ${ }^{3}$ Department of Biochemistry, Faculty of Medicine, Universitas Trisakti, Jl. Kyai Tapa No.1, Jakarta, Indonesia \\ *Corresponding author. E-mail: septelia@gmail.com
}

Received date: Jan 23, 2019; Revised date: May 28, 2019; Accepted date: May 31, 2019

\section{Abstract}

B ACKGROUND: Glioblastoma multiforme (GBM) is a human malignant brain tumor which is arise from glial cells. Our previous study proved that GBM cells proliferation increased after treating by conditioned medium of umbilical cord-derived mesenchymal stem cells (CM-UCSCs). Cells proliferation is probably mediated by tumor necrosis factor (TNF)- $\alpha$ which could bind to membrane receptor and induce signaling pathway. Therefore, this research was intended to analyze the mRNA expression of TNF- $\alpha$ signaling pathway molecules on CM-treated GBM cells by measuring TNF receptor 1 and 2 (TNFR1 and TNFR2), TNFR associated factor 2 (TRAF2), nuclear factor kappa B (NF-kB) mRNA level, and TNFR2 protein level.

METHODS: UCSCs and human glioblastoma T98G cells were cultured and harvested after $80 \%$ confluence. $\mathrm{CM}$ was prepared by growing UCSCs in serum alpha Minimum Essential Media ( $\alpha$-MEM) for 24 hours. Fifty percent concentration of CM-UCSCs was used to treat

\section{Introduction}

Glioblastoma multiforme (GBM) is the primary malignant brain tumor that originates from glial cells and it develops mostly in the brain hemisphere. Until now the etiology of GBM is not known with certainty. The heterogeneity of glioblastoma cell formers resulted in lower successful
T98G cells for 24 hours. TNF- $\alpha$ level in CM-UCSC was detected using enzyme linked-immunosorbent assay (ELISA), while the expression of TNFR1, TNFR2, TRAF2 and NF- $\kappa B$ were detected using quantitative Reverse Transcriptase Polymerase Chain Reaction (qRT-PCR), and TNFR2 protein level was detected using sandwich ELISA.

RESULTS: TNF- $\alpha$ level was detected in CM-UCSCs $4.4 \mathrm{pg} / \mathrm{mL}$. Moreover, the expression of TNFR1, TNFR2, TRAF2 and NF- $\mathrm{kB}$ were significantly 1.4-fold, 4.9-fold, 5.6-fold, 1.8-fold respectively higher in T98G treated cells than control. TNFR2 protein level in T98G treated cells was $11.57 \mathrm{pg} / \mathrm{mg}$ protein higher than control.

CONCLUSION: The expression of molecules involved in TNF- $\alpha$ signaling pathway were up regulated in T98G cells treated by CM-UCSCs.

KEYWORDS: CM-UCSCs, TNFR1, TNFR2, TRAF2, NF-kB, T98G cells

Indones Biomed J. 2019; 11(2): 217-24 therapeutic.(1) One of the factors that is considered to affect glioma growth is the role of tumor microenvironment (TME) which have multiple properties.(2) Mesenchymal stem cells (MSCs) as a part of tumor microenvironment secrete various growth factors, cytokines, chemokines which is called secretome that could increase proliferation and metastasis of tumors and also promote apoptosis through paracrine interactions.(3) According to previous study found 
that apoptosis occurred in glioblastoma cells treated with umbilical cord stem cells (UCSC) by direct co culture.(4) But in other study reported that treating glioblastoma U251 cell with secretome from human umbilical cord perivascular cells (HUCPCs) lead to increase viability, survival, and migration of glioblastoma cells.(5)

Tumor necrosis factor (TNF)- $\alpha$ is a cytokine which could be found in secretome has various role in the host immune defense system, inflammation process, cancer cells progression and metastasis.(6) TNF has a dual role in the development of cancer cells either increase cell apoptosis or increase cancer cell proliferation.(7) TNF which are secreted by MSCs, is synthesized as a molecule propeptide $26 \mathrm{kDa}$ which are bound to transmembrane (tm-TNF). TNF is cleaved by TNF activating converting enzyme (TACE) to become active form molecule $17 \mathrm{kDa}$ which are called soluble TNF (sTNF). Both of these molecules can act as ligand on TNF receptors (TNFR). There are two types of TNFR namely TNFR1 and TNFR2. Both of these receptors have different function in cell signaling so the response depends on activation ligand which secreted in TME.(8) The basic difference between TNFR1 and TNFR2 is the location of the death domain (DD) in the cytoplasm of the cell. TNFR1 has DD region so that if the TNF molecule binds to its receptor, a cell apoptosis response will occur. Whereas TNFR2 does not have the region of DD so the response arises in the form of cell proliferation. TNFR1 also has another ability to activate the cell proliferation pathway through the recruitment of the adapter protein TNFR associated factor 2 (TRAF2) and protein nuclear factor kappa B (NF-kB) when TNF binds to TNFR1.(9)

There are a few studies which discuss the enhancement of GBM cells proliferation after treating by conditioned medium (CM) of MSCs. Recent study found that cell viability, tumor growth and proliferation cells of U251 glioblastoma cells increased after treating by $\mathrm{CM}$ of human umbilical cord perivascular cells (HUCPVCs).(5) Another study using two groups of breast cancer cell lines such as MDA-MB-468 and SK-BR3 showed that TNF- $\alpha$ could contributed in development of cancer cells progression through the TNFR1-NF- $\kappa$ B axis.(10) Our previous study conclude that treated T98G cells with CM of MSCs could rise pluripotency marker such as Sex determining region Y box 2 (SOX2), Octamer binding transcription factor 4 (OCT-4), and homeobox Nanog protein.(11) In addition, our another study proved that CM-UCSCs does not seems affect apoptosis but tend to increase cell proliferation in T98G cells.(12) Nevertheless, signaling cascade pathway in GBM cells treated with $\mathrm{CM}$ of umbilical cord-derived mesenchymal stem cells (UCMSC) is not well established. Therefore, this research aims to detect the presence TNF- $\alpha$ molecule in CM-UCMSC and it's signaling cascade pathway regulation by measuring mRNA level of TNFR1, TNFR2, TRAF2 and NF- $\kappa B$ collected from GBM that had been previously treated by CM-UCMSC.

\section{Methods}

\section{Culture of Glioblastoma T98G Cells}

Glioblastoma T98G cells (American type culture collection (ATCC)) Number CRL-1690TM) were provided from our previous research.(13) GBM cells were grown in Gibco Dulbecco's Modified Eagle Medium (DMEM) high glucose (Thermo Fisher Scientific, Massachusetts, USA) on T-Flask $25 \mathrm{~cm}^{2}$ with the addition of Sodium bicarbonate, $10 \%$ fetal bovine serum, $1 \%$ penicillin-streptomycin, $1 \%$ amphotericin. Culture cells were placed in incubator with $5 \% \mathrm{CO}_{2}, 37^{\circ} \mathrm{C}$ temperature and $95 \% \mathrm{O}_{2}$ conditions. Cells were grown until the $80 \%$ subconfluence and then harvested. Medium was replaced every 3 days.(13)

\section{Culture of UCSCs and Preparation of CM}

UCSCs were provided from our preious research (11) which were grown in a Gibco $\alpha$-Minimum Essential Medium ( $\alpha$-MEM) (Thermo Fisher Scientific) on a $25 \mathrm{~cm}^{2}$ T-Flask with $10 \%$ fetal bovine serum, $1 \%$ penicillin-streptomycin, and $1 \%$ amphotericin. Culture cells were placed in chamber with $37^{\circ} \mathrm{C}, 5 \%$ saturation $\mathrm{CO}_{2}$, and $95 \%$ saturation $\mathrm{O}_{2}$. Cells were grown to $80 \%$ confluence. Conditioned medium was prepared by growing UCSCs in serum free $\alpha$-MEM for 24 hours. UCSCs were removed and medium was taken and filtered, then diluted for 50\% (v/v) using DMEM high glucose. Fifty percent concentration of CM-UCSCs was used to treat T98G cells for 24 hours. Control T98G cells were cultured with $\alpha$-MEM and DMEM with ratio 1:1. CM treated cells means T98G cells were cultured with CMUCSCs and $\alpha$-MEM with ratio $1: 1 .(14)$

\section{Protein Sample Preparation}

Protein isolation was done by radio immunoprecipitation assay (RIPA) buffer (Thermo Fisher Scientific) through the protocol kit. Twenty-five $\mu \mathrm{L}$ was added into CM-treated T98G cells with 225 cold phosphate buffered saline (PBS). Then, micro tube was incubated with ice for 30 minutes and vortexed every 10 minutes. After that, micro tube was centrifuged in $12.000 \mathrm{rpm}, 4^{\circ} \mathrm{C}$, for 10 minutes. Supernatant was removed into another micro tube and put in $-80^{\circ} \mathrm{C}$. 
Enzyme Linked Imunoabsorbance Assay (ELISA) of TNF- $\alpha$ and TNFR2

TNF- $\alpha$ level from conditioned medium was measured using sandwich ELISA method with human ELISA TNF- $\alpha$ assay kit (Catalogue \#E-EL-H0109, Elabscience, Texas, USA). Meanwhile, TNFR2 level was measured using sandwich ELISA method with human ELISA TNFR2 assay kit (Catalogue \#Ab 100643, Abcam, Cambridge, USA). All procedures were performed according to kit protocol. The plate was read using Varioscan ${ }^{\circledR}$ ELISA reader (Thermo Fisher Scientific) in the absorbance $450 \mathrm{~nm}$. TNF- $\alpha$ and TNFR2 concentrations were calculated based on standard curve plotted.

\section{RNA Isolation and Quantitative Reverse Transcriptase Polymerase Chain Reaction (qRT-PCR)}

TriPure Isolation (Roche, Basel, Switzerland) reagent was used to isolate of total RNA of condition medium-treated glioblastoma multiforme cells according to kit protocol. Relative mRNA expression of TNF- $\alpha$ signaling pathway were detected using SensiFAST SYBR ${ }^{\circledR}$ No ROX Real Time PCR kits (Bioline, Nottingham, United Kingdom) and run in Applied Biosystem 7500 q-PCR machine (Thermo Fisher Scientific). All samples were done in triplicate and the expressions were calculated using delta CT method. (13) Annealing temperature for TNFR1, TRAF2 and NF-кB were $55^{\circ} \mathrm{C}$ while annealing temperature TNFR2 was $60^{\circ} \mathrm{C}$. Annealing temperature reference gene $18 \mathrm{sRNA}$ was $59^{\circ} \mathrm{C}$. List of primers were provided in Table 1.

\section{Statistical Analysis}

Statistical test analysis was performed using student t-test. The experiment was carried out three times. Data analysis was calculated with IBM SPSS software 23 (IBM Corporation, New York, USA)

\section{Results}

TNF- $\alpha$ protein was detected in CM-UCSC. TNF- $\alpha$ level was detected $4.4 \mathrm{pg} / \mathrm{mL}$ in CM-UCSCs. There was no significant morphology changes on T98G GBM cells (Figure 1) after 24 hours incubation with 50\% CM-MSC (v/v).

TNFR1, TNFR2, TRAF2 and NF- $\mathrm{B}$ mRNA expression were significantly higher in CM-UCSCs. In Figure 2,3,4, the ratio of mRNA expression in T98G GMB cells treated with CM-UCSCs were higher 1.4-fold, 5.6fold, and 1.8-fold, respectively, than control. The increasing of those mRNA expression probable occurred due to binding of TNF in CM with TNFR1 in membrane which made a recruitment to TRAF2 and NFkB intracellularly. However, the binding of TNF- $\alpha$ to its receptor should be proved using Electrophoretic mobility shift assay (EMSA).

TNFR2 protein level were significantly higher in CM-UCSCs treated cells than control. TNFR2 protein level in CM-treated T98G cells was $11.57 \mathrm{pg} / \mathrm{mg}$ protein while TNFR2 protein level in control medium was $7.72 \mathrm{pg} / \mathrm{mg}$ protein. This findings also revealed higher mRNA TNFR2 parallel with higher protein level in glioblastoma CMtreated cells.

\section{Discussion}

Our research proved that TNF- $\alpha$ was detected $4.4 \mathrm{pg} / \mathrm{mL}$ in CM-UCMSCs. Although the detection range of the ELISA

Tabel 1. List of primers sequences.

\begin{tabular}{|c|c|c|c|c|}
\hline \multicolumn{2}{|c|}{ Gene } & \multirow{2}{*}{$\frac{\text { Primer Sequences }}{\text { 5' TGC CTA CCC CAG ATT GAG AA 3' }}$} & \multirow{2}{*}{$\begin{array}{c}\text { Amplicon } \\
169 \mathrm{bp}\end{array}$} & \multirow{2}{*}{$\begin{array}{c}\text { References } \\
(15)\end{array}$} \\
\hline TNFR1 & Forward & & & \\
\hline & Reverse & 5' ATT TCC CAC AAA CAA TGG AGT AG 3' & & \\
\hline \multirow[t]{2}{*}{ TNFR2 } & Forward & 5' ATT CTG GGA GGA AGC AGG TT 3' & $236 \mathrm{bp}$ & (4) \\
\hline & Reverse & 5' AGC CAG CCA GTC TGA CAT CT 3' & & \\
\hline \multirow[t]{2}{*}{ TRAF2 } & Forward & 5' CAC ACC TGT CCC TCT TCT TTG 3' & $100 \mathrm{bp}$ & $(16)$ \\
\hline & Reverse & 5' TTC TGG TCG AGC AGC ATT AAG 3' & & \\
\hline \multirow[t]{2}{*}{$\mathrm{NF} \kappa \mathrm{B}$} & Forward & 5' CGC TTA GGA GGG AGA GCC CA 3' & $190 \mathrm{bp}$ & (17) \\
\hline & Reverse & 5' TGG GCC ATC TGT TGG CAG TG 3' & & \\
\hline \multirow[t]{2}{*}{ 18s RNA } & Forward & 5' AAA CGG CTA CCA CAT CCA AG 3' & $155 \mathrm{bp}$ & $(18)$ \\
\hline & Reverse & 5' CCT CCA ATG GAT CCT CGT TA 3' & & \\
\hline
\end{tabular}



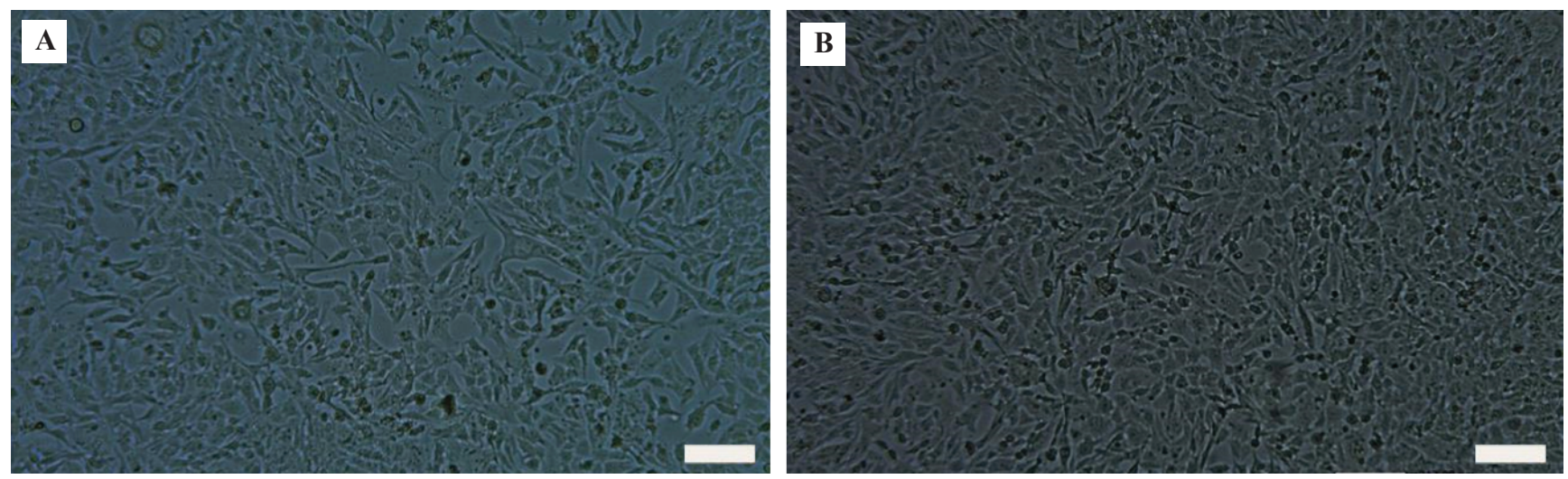

Figure 1. No changes in morphological of T98G cells with 24 hours incubation. A: control T98G cells with $50 \%$ concentration of $\alpha$-MEM and DMEM (v/v); B: CM-treated T98G cells with the $50 \%$ concentration of CM and $\alpha$-MEM (v/v). White bar: $213 \mu \mathrm{m}$.

kit was 7.81-500 $\mathrm{pg} / \mathrm{mL}$, however the sensitivity of the kit was $4.6 \mathrm{pg} / \mathrm{mL}$. Therefore, TNF- $\alpha$ in our CM could be still detected. The low level of TNF- $\alpha$ in our CM probably due to the short duration of CM collection (only 24 hours collection). In other study, TNF- $\alpha$ was detected $8.5 \pm 3.5 \mathrm{pg} /$ $\mathrm{mL}$ after 14 days collection.(19) There was no significant morphological changes T98G GBM cells after 24 hours incubation with umbilical cord derived MSCs. Expression of TNF $\alpha$ signaling pathway (TNFR1, TNFR2, TRAF2NFkB mRNA) was upregulated in CM-treated T98G cells. The mRNA expression of TNFR2 was significantly higher compared to TNFR1 mRNA expression. Moreover, TNFR2 protein level was significantly higher in CM-treated T98G cells compared to control.

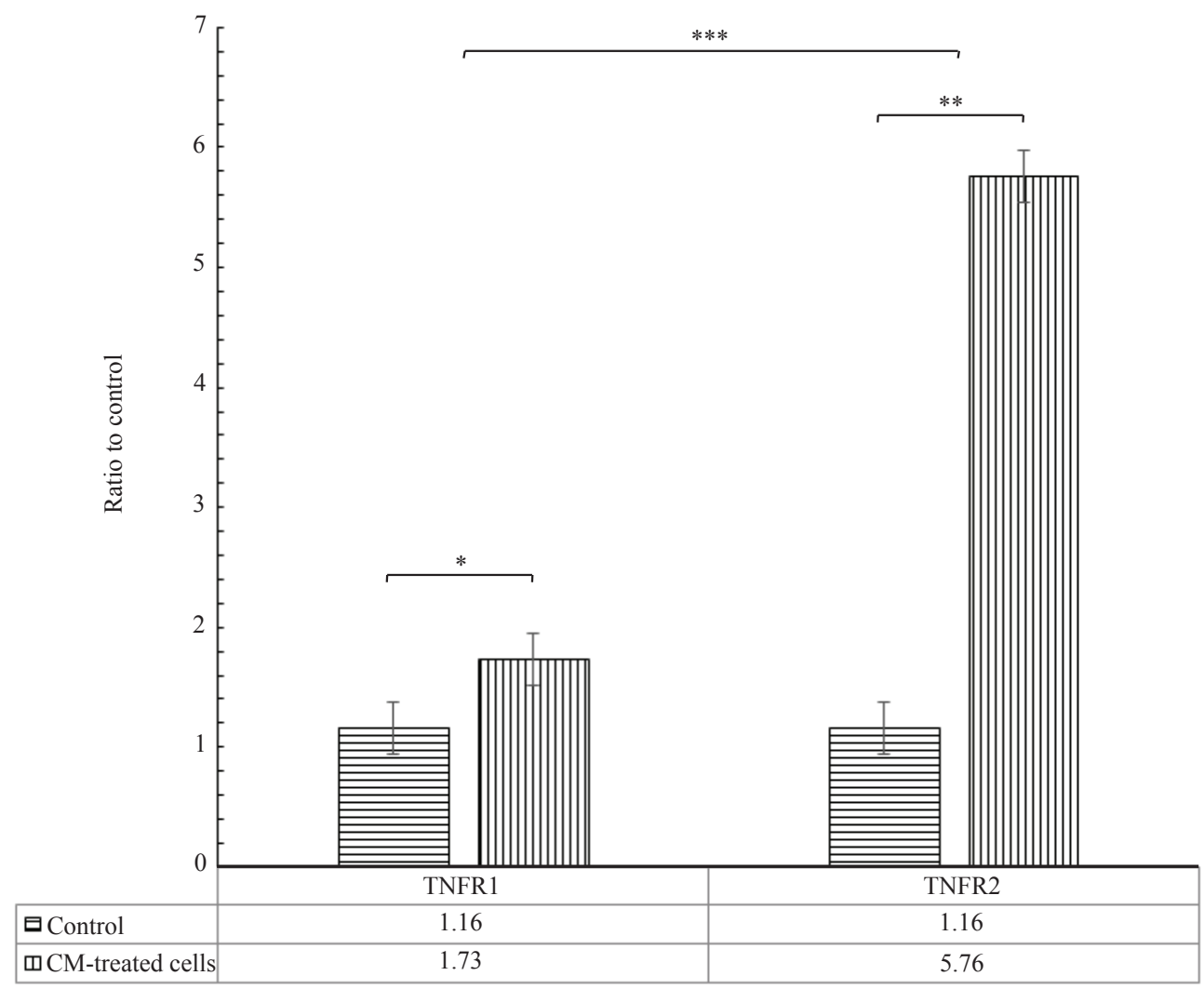

Figure 2. TNFR1 and TNFR2 mRNA expression. Total RNA in the amount of $100 \mathrm{ng}$ from glioblastoma T98G cell was amplified using qRT-PCR to detect TNFR1 and TNFR2 mRNA expression. The expression was measured with Livak method with $18 \mathrm{~s}$ RNA as reference gene. TNFR1 expression was 1.4 -fold $*(p=0.038)$, TNFR2 expression was 4.9 -fold $* *(p=0.001)$. TNFR2 mRNA expression 3.3 -fold significantly higher than TNFR1 $* * *(p=0.000)$. All data displayed in mean $\pm \mathrm{SE}(\mathrm{n}=9)$. Control means T98G cells were cultured with $\alpha$-MEM and DMEM with ratio 1:1. CM treated cells means T98G cells were cultured with CM-UCSCs and $\alpha$-MEM with ratio 1:1. 


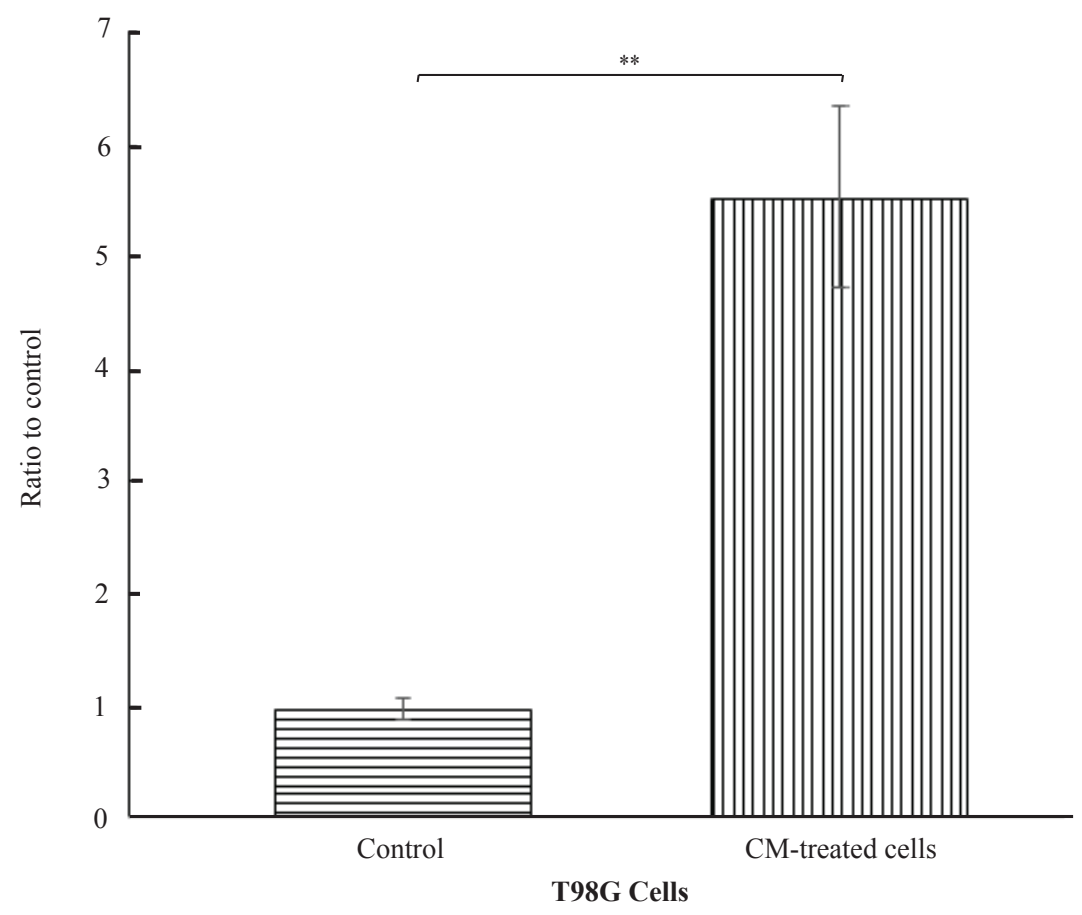

Figure 3. TRAF2 mRNA expression. Total RNA in the amount of $100 \mathrm{ng}$ from glioblastoma T98G cell was amplified using qRT-PCR to detect TRAF2 mRNA expression. The expression was measured with Livak method with 18s RNA as reference gene. TRAF2 expression was 5.6-fold $* *(p=0.001)$. All data was displayed in mean \pm SE $(n=8)$.
TNF- $\alpha$ is a cytokines which can act in inflammation and host immune defense which contained in the TME. Proteins and MSCs could influence cell viability, proliferation and metastasis of cancer cells. In different circumstances, proteins in the TME could also increase apoptosis. Impressive study using rat with fibrosarcoma proved that administration of TNF combined with chemotherapy agents could damage blood vessels followed by entering the chemotherapeutic substances into the tissue around the tumor which cause apoptosis of tumor cells.(20) However another study found that TNF- $\alpha$ could promote chemoresistance in breast cancer. Moreover, TNF- $\alpha$ could promote cancer cell proliferation through TNFR1-NF- $\kappa$ B axis.(10)

Our discovery found that TNF- $\alpha$ cytokines was detected in CM-UCSCs. It indicated that umbilical cord derived MSCs secrete this cytokine which probable play a role in tumor growth and cells proliferation. Interesting study about CM-UCMSCs cell showed that cytokine, chemokine

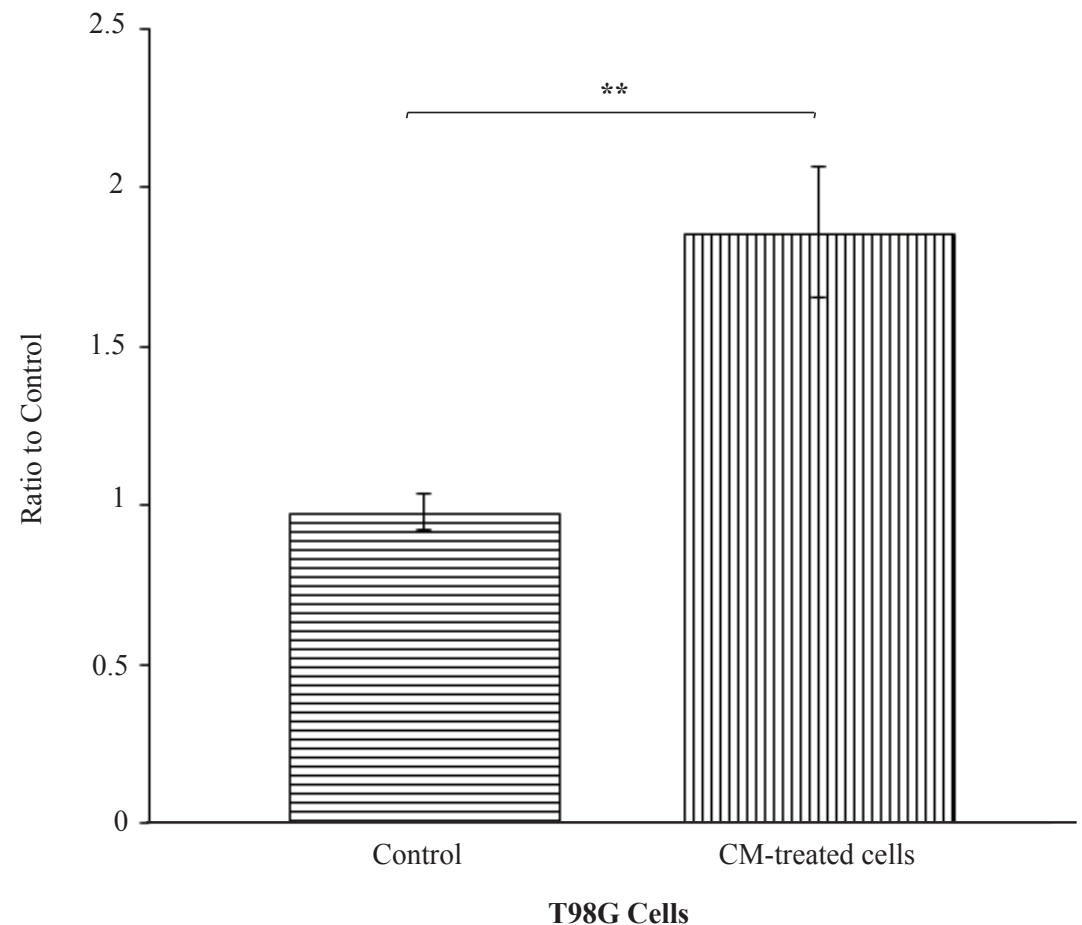

Figure 4. NF-кB mRNA expression. Total RNA in the amount of $100 \mathrm{ng}$ from glioblastoma T98G cell was amplified using qRT-PCR to detect NF-kB mRNA expression. The expression was measured with Livak method with 18s RNA as reference gene. NF$\mathrm{kB}$ expression was 1.8 -fold $* *(p=0.001)$. All data was displayed in mean $\pm \mathrm{SE}(\mathrm{n}=8)$. 


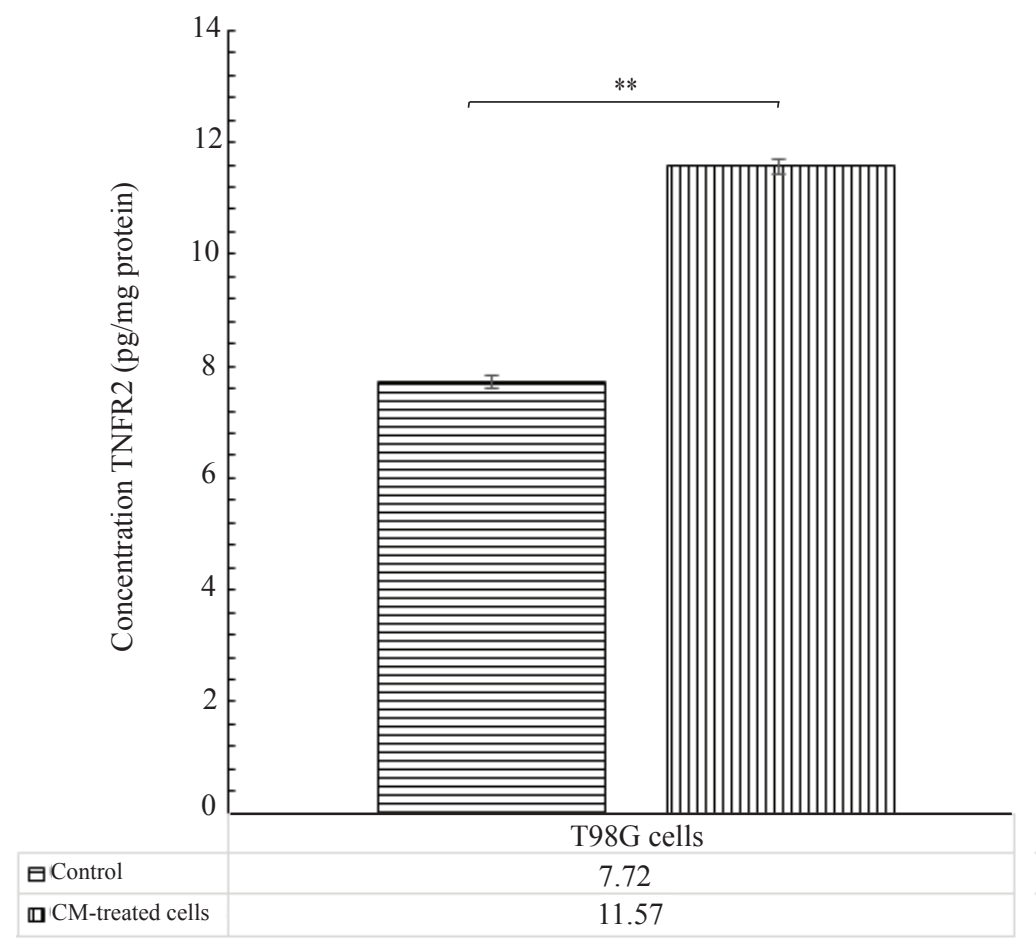

Figure 5. TNFR2 level protein. Protein sample in the amount of $100 \mu \mathrm{L}$ was used to measure TNFR2 level using ELISA with sandwich ELISA method. Protein TNFR2 level concentration was measured with absorbance $450 \mathrm{~nm}$. TNFR2 concentration in CM treated T98G cells was $11.57 \mathrm{pg} / \mathrm{mg}$ protein while concentration in control was $7.72 \mathrm{pg} / \mathrm{mg}$ protein $* *(p=0.001)$. All data displayed in mean $\pm \mathrm{SE}(\mathrm{n}=6)$. and growth factors such as TNF- $\alpha$ and interleukin (IL-6) play a role in tissue healing and inflammation.(19) Another study using GBM cells showed that cytokine and chemokine in CM-UCMSCs could make interaction with the GBM cells through paracrine communication which supported cancer stem cell (CSC) glioblastoma growth.(21)

By knowing the content of the $\mathrm{CM}$, it could be predicted the signaling pathway of this molecule which support our previous finding about the enhancement of GBM cells proliferation after treating by CM-UCSCs. The existence of TNF- $\alpha$ in CM probably could activate signaling pathway of GBM cells proliferation through binding of TNF- $\alpha$ with its receptors (TNFR1 and TNFR2 receptors) that was indicated by up regulation of TNFR1, TNFR2, TRAF2 and NFkB mRNA expression in this research. Interesting study using human UCSC and their exosome vesicles could increase lung adenocarcinoma growth in vivo which injected to nude mice.(22) Recently, study from colon cancer found that treated HCT-116 cells with TNF- $\alpha$ lead to invasion and migration cancer cells. It was activated by extracellular receptor kinase (ERK)1/2 pathway which up regulated trophoblast cell surface antigen 2 (TROP2) protein level.(23) Our previous study proved that T98G GBM cells treated with CM-UCSCs tend to increase proliferation cells. However there's no significant effect on apoptosis cells in T98G cells control and CM-treated.(12) From Figure 1, we can conclude that there was no morphological changes with $\mathrm{T} 98 \mathrm{G}$ glioblastoma multiforme cells treated with CM-
UCSC. However, it seemed that CM-treated T98G cells tend to more proliferate than control after 24 hours incubation.

From Figure 2, the increased of TNFR1 and TNFR2 expression probably could activate cell proliferation signaling pathways, particularly through the recruitment of adapter proteins in the cytoplasm, TRAF. TNFR2 expression higher 3.3-fold than TNFR1 because affinity TNF- $\alpha$ to bind with TNFR2 was 5 times higher than TNFR1.(24) When TNF $\alpha$ bind to TNF receptor, they could activate protein adaptor in cytoplasm. TNFR1 could activate TNF receptor associated death domain (TRADD) then activated apoptosis pathway through caspase protein. Another activation by TRADD was recruited TRAF2 (TNF receptor associated factor 2 ) which could lead activation of NF- $\mathrm{KB}$ as transcription factor in cell survival, cancer progression, and metastasis.(25) At the same time, the binding of TNF- $\alpha$ to TNFR2 will recruit TRAF2 and lead to activation of NFאB as transcription factor.

Figure 3 proved that TRAF2 was recruited, probably due to binding of TNF a with TNFR1 and TNFR2. Recruitment TRAF2 protein adapter in the cytoplasm resulted recruitment of other proteins that generate cell proliferation signals such as $\mathrm{NF}-\kappa \mathrm{B}$ which was proved by increasing its expression (Figure 4). NF- $\mathrm{kB}$ is one of the protein adaptor which is recruited through TRAF2 activation. A prostate cancer study showed that up regulation of TRAF2 associated with poor recurrence of metastatic cancer.(16) TNF- $\alpha$ which contained in CM could induce NF- $\kappa B$ through 
canonical pathway. Lately, breast cancer study proved that higher NF- $\mathrm{KB}$ expression lead to proliferation of MDAMB-468.(10)

Up regulation of TNFR2 expression in our research could activate NF- $\kappa B$ expression as a transcription factors which regulate cell survival, proliferation and metastasis. According to previous study found that $\mathrm{NF \kappa B}$ has a role in maintenance glioblastoma cancer stem cell which causes up regulation of pluripotency marker, chemo resistance, and low survival rate.(26) Therefore, NF- $\mathrm{KB}$ could be targeted as therapeutic molecule that suppression of NF- $\kappa B$ made tumor growth slower.(27) In our study, the increase of TNFR2 mRNA expression was followed by increasing of TNFR2 protein level as shown in Figure 5. Breast cancer study proved that TNF- $\alpha$ which bind to TNFR2 could increase phosphorylation of protein adaptor p38, JNK and ERK.(28) Activation of TNFR2 caused recruitment of mitogen-activated protein kinases (MAPK), ERK, and NF- $\mathrm{NB}$ pathway that lead to stimulate proliferation response. The protein level of TNFR2 was 4 times higher than TNFR1 in human epithelial cells treated by TNF- $\alpha$ and lovastatin.(29) The limitation of this study is expression analysis of molecules involved in TNF- $\alpha$ signaling pathway only measured at mRNA level, except for TNFR2. Protein expression analysis should be measured to ensure that this treatment also affect protein level. In addition, further research is needed by blocking TNF- $\alpha$ using specific inhibitor to prove that the TNF- $\alpha$ signaling pathway is truly induced by this treatment.

\section{Conclusion}

There was an increase of TNF- $\alpha$ receptor, TRAF2 and NF- $\kappa B$ mRNA expression in GBM cells treated by CMUCSCs.

\section{Acknowledgements}

This research was funded by Direktorat Riset dan Pengabdian Masyarakat Universitas Indonesia (DRPMUI).

\section{References}

1. Hanif F, Muzaffar K, Perveen K, Malhi SM, Simjee SU. Glioblastoma multiforme: A review of its epidemiology and pathogenesis through clinical presentation and treatment. Asian Pac J Cancer P. 2017; 18: 3-9.
2. Iser IC, Ceschini SM, Onzi GR, Bertoni APS, Lens Guido, Wink MR. Conditioned medium from adipose-derived stem cells (ADSCs) promotes conditioned medium from adipose-derived stem cells (ADSCs) promotes epithelial-to-mesenchymal-like transition (EMT-Like ) in glioma cells in vitro. Mol Neurobiol. 2016; 53: 7184-99.

3. Koontongkaew S. The tumor microenvironment contribution to development, growth, invasion and metastasis of head and neck squamous cell carcinomas. J Cancer. 2013; 4: 66-83.

4. Akimoto K, Kimura K, Nagano M, Takano S, To'a Salazar G, Yamashita $\mathrm{T}$, et al. Umbilical cord blood-derived mesenchymal stem cells inhibit, but adipose tissue-derived mesenchymal stem cells promote, glioblastoma multiforme proliferation. Stem Cells Dev. 2013; 22: 1370-86.

5. Vieira de Castro J, Gomes ED, Grania S, Anjo SI, Baltazar F, Manadas B, et al. Impact of mesenchymal stem cells' secretome on glioblastoma pathophysiology. J Transl Med. 2017; 15: 200. doi: 10.1186/s12967-017-1303-8.

6. Cunningham CJ, Redondo-castro E, Allan SM. The therapeutic potential of the mesenchymal stem cell secretome in ischaemic stroke. J Cereb Blood Flow Metab. 2018; 38: 1276-92.

7. Ham B, Fernandez MC, Costa ZD, Brodt P. The diverse roles of the $\mathrm{TNF}$ axis in cancer progression and metastasis. Trends Cancer Res. 2016; 11: 1-27.

8. Martínez-Reza I, Díaz L, García-Becerra R. Preclinical and clinical aspects of TNF- $\alpha$ and its receptors TNFR1 and TNFR2 in breast cancer. J Biomed Sci. 2017; 24: 90. doi: 10.1186/s12929-0170398-9.

9. Chopra M, Lang I, Salzmann S, Pachel C, Kraus S, Bauerlein CA, et al. Tumor necrosis factor induces tumor promoting and anti-tumoral effects on pancreatic cancer via TNFR1. Plos One. 2013; 8: e75737. doi: 10.1371/journal.pone.0075737.

10. Cai X, Cao C, Li J, Chen F, Zhang S, Liu B, et al. Inflammatory factor TNF- $\alpha$ promotes the growth of breast cancer via the positive feedback loop of TNFR1/NF- $\kappa$ B and/or p38. Oncotarget. 2017; 8: 58338-52.

11. Hardiany NS, Huang P, Dewi S, Paramita R, Wanandi SI. Analysis of pluripotency marker expression in human glioblastoma multiforme cells treated with conditioned medium of umbilical cord-derived mesenchymal stem cells. F1000Research. 2018; 7: 106. doi: 10.12688/f1000research.13154.1.

12. Hardiany NS, Yohana, Wanandi SI. The impact of conditioned medium of umbilical cord-derived mesenchymal stem cells toward apoptosis and proliferation of glioblastoma multiforme cells. IOP Conf Ser Earth Environ Sci. 2019; 217: 012035. doi: 10.1088/17551315/217/1/012035.

13. Hardiany NS, Sadikin M, Siregar N, Wanandi SI. The suppression of manganese superoxide dismutase decreased the survival of human glioblastoma multiforme T98G cells. Med J Indones. 2017; 26: 19-25.

14. Purnamawati P, Pawitan JA, Rachman A, Wanandi SI. Effects of umbilical cord- and adipose-derived stem cell secretomes on ALDH1A3 expression and autocrine TGF- $\beta 1$ signaling in human breast cancer stem cells. F1000Research. 2018; 7: 249. doi: 10.12688/f1000research.13609.1

15. Zhang K, Li QI, Kang X, Wang Y, Wang S. Identification and functional characterization of IncRNAs acting as ceRNA involved in the malignant progression of glioblastoma multiforme. Oncology Report. 2016; 36: 2911-25.

16. Wei B, Liang J, Hu J, Mi Y, Ruan J, Zhang J, et al. TRAF2 is a valuable prognostic biomarker in patients with prostate cancer. Med Sci Monit. 2017; 23: 4192-204. 
17. Fashi M, Agha-alinejad H, Mahabadi HA, Rezaei B, Pakrad B, Rezaei S. The Effects of aerobic exercise on NF- $\kappa B$ and TNF- $\alpha$ in lung tissue of male rat. Novel Biomed. 2015; 3: 131-4.

18. Hardiany NS, Mulyawan W, Wanandi SI. Correlation between oxidative stress and tumor grade in glioma cells from patients in Jakarta. Med J Indones. 2012; 21: 122-9.

19. Mehling BM, Manvelyan M, Benesh G, Wu DC. Characterization of human umbilical cord mesenchymal stem cells-derived conditioned medium. J Stem Cell Res Ther. 2016; 1: 218-20.

20. Ten Hagen TL, Van Der Veen AH, Nooijen PT, Van Tiel ST, Seynhaeve $\mathrm{AL}$, Egermont AM. Low dose tumor necrosis-alpha augments antitumor activity of stealth liposomal doxorubicin (DOXIL) in soft tissue sarcoma-bearing rats. Int J Cancer. 2000; 87: 829-37.

21. Bajetto A, Pattarozzi A, Corsaro A, Barbieri F, Daga A, Bosio A, et al. Different effects of human umbilical cord mesenchymal stem cells on glioblastoma stem cells by direct cell interaction or via released soluble factors. Front Cell Neurosci. 2017; 11: 312. doi: 10.3389/ fncel.2017.00312.

22. Dong L, Pu Y, Zhang L, Qi Q, Xu L, Li W, et al. Human umbilical cord mesenchymal stem cell-derived extracellular vesicles promote lung adenocarcinoma growth by transferring miR-410. Cell Death Dis. 2018; 9: 218. doi: 10.1038/s41419-018-0323-5.
23. Zhao P, Zhang Z. TNF- $\alpha$ promotes colon cancer cell migration and invasion by upregulating TROP-2. Oncol Lett. 2018; 15: 3820-7.

24. Chowdhury I, Bhat GK. Tumor Necrosis Factor (TNF) - From Bench to Bed Side. New York: Nova Science Publisher; 2009.

25. Puliyappadamba VT, Chakraborty S, Hatanpaa KJ, Habib AA. The role of NF-kB in the pathogenesis of glioma. Mol Cell Oncol. 2014; 1: e963478. doi: 10.4161/23723548.2014.963478.

26. Rinkenbaugh AL, Cogswell PC, Calamini B, Dunn DE, Persson AI, Weiss WA, et al. IKK / NF- $\mathrm{KB}$ signaling contributes to glioblastoma stem cell maintenance. Oncotarget. 2016; 7: 69173-87.

27. Friedmann-morvinski D, Narasimamurthy R, Xia Y, Myskiw C, Soda Y, Verma IM. Targeting NFkB in glioblastoma : a therapeutic approach. Sci Adv. 2016; 2: e1501292. doi: 10.1126/ sciadv. 1501292.

28. Hu X, Li B, Li X, Zhao X, Wan L, Lin G, et al. Transmembrane TNF$\alpha$ promotes suppressive activities of myeloid-derived suppressor cells via TNFR2. J Imunol. 2018; 192: 1320-31.

29. Nubel T, Chmitt SS, Aina BK, Fritz G. Lovastatin stimulates p 75 TNF receptor (TNFR2) expression in primary human endothelial cells. Int J Mol Med. 2005; 27: 1139-45. 